\title{
ANÁLISE DA COMPETITIVIDADE DO SETOR DE FERTILIZANTES DA REGIÃO NORDESTE
}

\author{
Analysis of competitiveness of the fertilizers sector from the Northeast region
}

\author{
Carlos Gilberto Pinheiro Barbalho Júnior ${ }^{[a]}$, Antônio André Cunha Callado ${ }^{[b]}$
}

[a] [a] Estudante de Pós-Graduação em Gestão de Negócios da Universidade Federal de Pernambuco (UFPE), Recife, PE - Brasil, e-mail: carlosgilberto@agrofertil.com.br

[b] [b] Professor associado da Universidade Federal Ruralde Pernambuco (UFPE), Recife, PE-Brasil, e-mail: andrecallado@yahoo.com.br

\begin{abstract}
Resumo
Os fertilizantes químicos são produtos essenciais para o incremento da produtividade agrícola e são oriundos da mineração e da indústria petroquímica. O Brasil importa mais de $60 \%$ de todo fertilizante consumido no País - é o terceiro maior importador e o quarto maior consumidor de fertilizantes do mundo, atrás de China, EUA e Índia. O objetivo deste artigo foi estabelecer uma relação prática entre as forças direcionadoras da competitividade na indústria de fertilizantes do Nordeste do Brasil por meio do modelo de análise das cinco forças que dirigem a concorrência na indústria proposto por Porter (1986). Os dados foram obtidos a partir de pesquisa documental e de entrevistas semiestruturadas. Os entrevistados possuem status hierárquico capaz de dar acesso às informações estratégicas das empresas nas quais eles atuam. A intensidade da concorrência é alta, mas as principais barreiras de entrada estão relacionadas ao volume e à capitalização da empresa. A ameaça de produtos substitutos é muito pequena. Quanto ao poder de barganha dos fornecedores, há indícios de que esta seja uma força competitiva muito importante. Empresas de menor porte têm capacidade limitada para negociar com fornecedores. O poder de barganha dos compradores possui muitas similaridades com o poder dos fornecedores.
\end{abstract}

Palavras-chave: Competitividade. Estratégia. Agronegócio.

\begin{abstract}
Chemical fertilizers are essential products for enhancing agricultural productivity and they are from both mining and petrochemical industries. Brazil imports more than $60 \%$ of all fertilizer consumed, is the third largest importer and fourth largest consumer of fertilizers in the world, behind China, USA and India respectively. The aim of this paper was to establish a practical relationship between the forces driving competitiveness in the fertilizer industry in the Northeast of Brazil through the analysis model of five forces that drive competition in the industry proposed by Porter (1986). Data were collected through documentary research and semi-structured interviews. Respondents have hierarchical status can provide access to strategic information from companies in which they
\end{abstract}


operate. The intensity of competition is high, but the main barriers to entry are related to the volume and capitalization of the company. The threat of substitute products is very small. Concerning the bargaining power of suppliers, there are indications that this is a very important competitive force. Smaller companies have limited ability to negotiate with suppliers. Bargaining power of buyers has many similarities with the power suppliers.

Keywords: Competitiveness. Strategy. Agribusiness.

\section{INTRODUÇÃO}

Os fertilizantes constituem um dos principais insumos agrícolas e têm como fontes de matéria-prima produtos oriundos da petroquímica e da mineração. Destaca-se a importância dos fertilizantes nitrogenados, fosfatados e potássicos, que formam a base para as misturas NPK (DIAS; FERNANDES, 2006).

Os fertilizantes são essenciais para produtividade agrícola, sendo insumo preponderante no aumento da produtividade das culturas. A cadeia produtiva dos fertilizantes é composta por quatro segmentos distintos: o da extração mineral, que fornece as rochas fosfatadas e potássicas, o enxofre e o gás natural; o de produtos intermediários, como o ácido sulfúrico, o ácido fosfórico e a amônia anidra; o segmento da produção de fertilizantes simples (fertilizantes básicos); e o das indústrias de misturas fertilizantes NPK (DIAS; FERNADES, 2006).

A produção de fertilizantes no Brasil teve seu início na década de 50, quando a capacidade de produção estava apta a fornecer apenas $8 \%$ da demanda já utilizada. Na década de 60 ocorreu um aumento da produção com a expansão de indústrias do setor com investimentos governamentais e privados.

$\mathrm{Na}$ década de 70 , sob forte intervenção do Estado, iniciou-se uma nova fase no setor, com a criação do Plano Nacional para a Difusão de Fertilizantes e Calcários Agrícolas, para se conseguir a autossuficiência na produção interna, pois o consumo se dava com aumentos substanciais da década de 50 a 70 . Até a década de 80 , o setor foi beneficiado com mecanismos de proteção, apoiados por uma conjuntura favorável pela substituição das importações com a nacionalização da produção.

A partir da década de 80 ocorreu grande corte no crédito rural, o qual era subsidiado e o grande impulsionador do setor, causando um remodelamento com a substituição do fornecimento de crédito do tradicional sistema financeiro pelas indústrias de misturas fertilizantes, fazendo com que muitas empresas não suportassem assumir os riscos da agricultura, ocasionando fechamento de unidades fabris, redução da produção interna e do setor como um todo.

No fim da década de 80 , teve início a queda do protecionismo com o término das restrições quantitativas à importação dos fertilizantes. Mas foi na década de 90 que se deu por completo o processo de liberalismo, com o fim das alíquotas de importação e o processo de privatizações, causando total reestruturação do setor.

Com estes novos panoramas, verificou-se a entrada de capital internacional, com novos investimentos, fusões e aquisições de empresas de pequeno porte de caráter regionalizado. As principais aquisições se deram até o início de 2000 , e o setor vem numa certa estabilidade na macroestrutura, existindo ainda algum movimento natural de compra e venda de empresas, não tendo nenhuma grande mudança no ambiente do negócio em si (IFA, 2007).

O setor passou por um período de pequeno crescimento entre os anos de 2000 e 2004, aumentando o consumo de 20 para 23 milhões de toneladas. Em 2005 houve uma redução no consumo de fertilizantes, voltando este para o patamar do ano 2000 , graças à crise no setor de grãos, principalmente na cultura da soja.

Em 2007 o setor voltou a crescer fortemente, fechando mais de 24 milhões de toneladas, muito influenciado pelo otimismo não confirmado da indústria de açúcar e álcool e pela elevação de preços das principais commodities agrícolas, principalmente soja e milho, que obtiveram patamares de preços acima das altas históricas (ANDA, 2007).

No Brasil importa-se cerca de $66 \%$ dos fertilizantes (NPK) consumidos internamente (ANDA, 2007), sobretudo dos EUA (nitrogenados), da Rússia (nitrogenados e potássicos) e do Canadá (fosfatados 
e potássicos). O Brasil é hoje o quarto maior consumidor de fertilizantes do mundo, com $4,2 \%$ do total consumido, com uma produção nacional em cerca de 10 milhões de toneladas e importando cerca de 14 milhões de toneladas, pelas estimativas de entregas em 2007 (IFA, 2007).

O consumo de fertilizantes na América Latina corresponde a cerca de $8 \%$ do consumo mundial, sendo o Brasil o maior consumidor, com cerca de $50 \%$ deste consumo, seguido do México, com 15\%, e da Argentina, com 8\% (IFA, 2007). Em primeiro lugar no consumo mundial está a China, com $25,5 \%$, seguida dos EUA e da Índia, que concorrem ao segundo lugar, com aproximadamente $14 \%$ do total consumido cada (IFA, 2007).

Contudo, existem algumas peculiaridades entre o consumo de cada país. Do total de fertilizantes consumidos na China, $66,39 \%$ correspondem ao nitrogênio, enquanto nos EUA este valor atinge $57 \%$. No Brasil, 38,36\% do consumo total de NPK refere-se ao nutriente potássio.

Segundo Dias e Fernandes (2006), os fertilizantes podem ser classificados em três tipos:

- fertilizante mineral: produto de natureza fundamentalmente mineral, natural ou sintética, obtido por processo físico, químico ou físico-químico, fornecedor de um ou mais nutrientes das plantas;

- fertilizante orgânico: produto de natureza fundamentalmente orgânica, obtido por processo físico, químico, físico-químico ou bioquímico, natural ou controlado, com base em matériasprimas de origem industrial, urbana ou rural, vegetal ou animal, enriquecido ou não de nutrientes minerais;

- fertilizante organomineral: produto resultante da mistura física ou combinação de fertilizantes minerais e orgânicos.

Neste texto é utilizado o termo fertilizante para nos referirmos a fertilizante mineral, para simplificação da ideia do texto, sem perder o significado amplo, conforme descrito anteriormente, mas utilizando o termo normalmente utilizado no dia a dia desta indústria.

O desempenho da agropecuária brasileira é incomparável. Nenhum outro país teve um crescimento tão expressivo na agropecuária quanto o Brasil nos últimos anos. A safra de grãos, por exemplo, saltou de 57,8 milhões de toneladas para 123,2 milhões de toneladas entre as safras 1990/1991 e 2002/2003, conforme informações da Conab e IBGE. Nesse período, a evolução da pecuária também foi invejável, com destaque para a avicultura, cuja produção aumentou $234 \%$ - ou incríveis $16,7 \%$ ao ano -, passando de 2,3 milhões para 7,8 milhões de toneladas.

Outro aspecto importante a ser destacado é a interdependência do setor agrícola no negócio dos fertilizantes, sendo este um importante agente de mudanças no ambiente do negócio. O consumo de fertilizantes no Brasil está concentrado em algumas culturas, principalmente soja, milho e cana, que juntas representam um consumo de cerca de $70 \%$ de todo o fertilizante utilizado no País, causando relação direta entre as tendências macroeconômicas destas culturas com o setor em questão.

A dependência da demanda de fertilizantes no Brasil em relação à soja reproduz no setor de fertilizantes a volatilidade do preço internacional dessas commodities, que tem sofrido variações bruscas. Outras culturas que influenciam de forma regionalizada o consumo são: o café, o algodão, o arroz, o trigo, a citricultura, a batata, o tomate e a fruticultura de exportação (ANDA, 2007).

O Brasil possui mais de 367 milhões de hectares agricultáveis, sendo destes $75 \%$ já em atividade no agronegócio, restando cerca de 90 milhões de hectares disponíveis para agricultura. Isto significa que se nós cultivássemos estas áreas teríamos cerca de pelo menos 270 milhões de toneladas de soja a mais produzida, ou 630 milhões de toneladas de milho, ou ainda pelo menos 4,5 bilhões de toneladas de cana-de-açúcar.

Para se ter a real dimensão comparativa dos dias atuais, a safra de grãos projetada 2007/2008, que está sendo considerada muito boa para a agricultura nacional, atingirá cerca de 136 milhões de toneladas de grãos produzidos, ou seja, a área que ainda temos para crescer facilmente proporcionaria mais que o dobro da produção de hoje.

Mas ainda devemos olhar o desenvolvimento agrícola por outra ótica. Nós temos 220 milhões de hectares com pastagens; destas, estima-se que mais de 90 milhões sejam pastagens degradadas, o que nos proporciona uma área bastante expressiva do ponto de vista do potencial agrícola. 
Quadro 1 - Ocupação do território brasileiro

\begin{tabular}{lr}
\hline Área territorial ocupada & M ha \\
\hline Floresta Amazônica & 350 \\
Reservas legais & 55 \\
Pastagens cultivadas & 220 \\
Lavouras anuais & 42 \\
Culturas permanentes & 15 \\
Área agricultável disponível & 90 \\
Centros urbanos & 20 \\
Reflorestamento & 5 \\
Outros & 54 \\
TOTAL & 851 \\
\hline
\end{tabular}

Fonte: Adaptado de ANDA, 2006.

O objetivo deste artigo foi estabelecer uma relação prática entre as forças direcionadoras da competitividade na indústria de fertilizantes do Nordeste do Brasil a partir do modelo de análise das cinco forças que dirigem a concorrência na indústria proposto por Porter (1986).

\section{REFERENCIAL TEÓRICO}

Estratégia competitiva é o conjunto de planos, políticas, programas e ações desenvolvidos por uma empresa para ampliar ou manter, de modo sustentável, suas vantagens competitivas diante dos concorrentes. A estratégia competitiva é o posicionamento de um negócio em busca da valorização das suas principais características que o distingue dos seus concorrentes.

Todas as empresas possuem uma estratégia competitiva, seja ela explícita ou implícita. Ou seja, a estratégia pode ser desenvolvida explicitamente, por meio de um processo de planejamento prévio, ou ter evoluído naturalmente, por meio das atividades cotidianas dos setores existentes na empresa.

A estratégia começa com uma visão de futuro para a empresa e implica a definição clara de seu campo de atuação, a habilidade de previsão de possíveis reações às ações empreendidas e o direcionamento que a levará ao crescimento. A definição de objetivos, em si, não implica uma estratégia.

Aaker (2001) ressalta que existem infinitas maneiras de competir, mas considera que três fatores são determinantes para o estabelecimento de uma vantagem competitiva sustentável, a saber:
- o modo peloqual as empresas competem (estratégias de produto, posicionamento, fabricação e distribuição);

- as bases de competição das empresas (ativos e competências);

- onde a empresas competem (seleção dos produtos e mercados);

- com quem as empresas competem (seleção de concorrentes).

Os objetivos representam os fins que a empresa está tentando alcançar, enquanto a estratégia é o meio para alcançar esses fins. Considera-se que apenas fazer o que outros fazem, mas com maior eficácia operacional, não é propriamente ter uma estratégia. Está implícito no conceito que, para ter uma estratégia, precisamos atuar de forma diferente, com inteligência e planejamento.

Para Vasconcelos e Cyrino (2006), as teorias que abordam as estratégias empresariais a partir das vantagens competitivas podem ser classificadas em dois grupos distintos:

a) foco na origem das vantagens competitivas como atributo de posicionamento;

b) foco nas premissas da concorrência que geram performances superiores a partir das características internas das empresas.

O desenvolvimento de estratégias tem sido tradicionalmente abordado como um processo formal de planejamento, envolvendo, em geral, duas etapas. A primeira engloba a definição do negócio bem como a explicitação da missão da organização 
e seus princípios. A segunda é constituída das análises dos ambientes interno e externo à empresa, a determinação de objetivos com seus respectivos indicadores de acompanhamento e a formulação das estratégias correspondentes para alcançá-los.

Porter (1986) conceitua estratégia competitiva como sendo o desenvolvimento de uma fórmula ampla para o modo como uma empresa irá competir, bem como as políticas e metas necessárias para alcançar seus objetivos. A estratégia competitiva é "uma combinação dos fins (metas) que a empresa busca e dos meios (políticas) pelos quais está buscando chegar lá" (PORTER, 1986, p. 16).

Também foi descrita a estratégia competitiva como sendo um conjunto de ações ofensivas e defensivas de uma empresa para criar uma posição sustentável dentro da indústria, ações que são uma resposta às cinco forças competitivas que indicam como determinantes da natureza e grau de competição que cerca uma empresa. O conceito de estratégia pode ser empregado como guia do comportamento global da empresa.

Oliveira (2001), ao considerar o posicionamento de uma empresa dentro da indústria na qual ela atua como ponto central de uma estratégia, ressalta que a análise da posição competitiva é uma metodologia dotada de diversas técnicas e instrumentos que se propõem a fornecer informações básicas para o processo decisório inerente à estratégia estabelecida.

A análise da concorrência tem por objetivo desenvolver um perfil das estratégias e mudanças nessas estratégias que os concorrentes de uma indústria adotam, o movimento provável de cada concorrente em reação ao conjunto de alterações na indústria e as mudanças ambientais que poderiam vir a ocorrer.

A análise da concorrência serve para comparar os produtos em desenvolvimento com produtos já existentes no mercado, baseando-se em determinadas variáveis. Analisar a concorrência é analisar uma indústria ou um setor, entendendo-se como indústria um grupo de empresas que oferecem um produto ou uma categoria de produtos que são substitutos próximos uns dos outros.

Pela abordagem de mercado, concorrentes são empresas que atendem às mesmas necessidades dos clientes, portanto, assim que a empresa identificar os principais concorrentes ela deve descobrir suas estratégias, seus objetivos, suas forças e suas fraquezas.

A análise estrutural de uma indústria deve ser realizada por meio de cinco forças competitivas: o poder de negociação dos fornecedores, o poder de negociação dos compradores, a ameaça de produtos substitutos, a rivalidade entre os concorrentes existentes e a entrada de novos concorrentes (Figura 1). O grau da concorrência em uma indústria depende da influência dessas cinco forças competitivas básicas, as quais determinam o potencial de lucro final na indústria que é medido com base no retorno do capital investido em longo prazo.

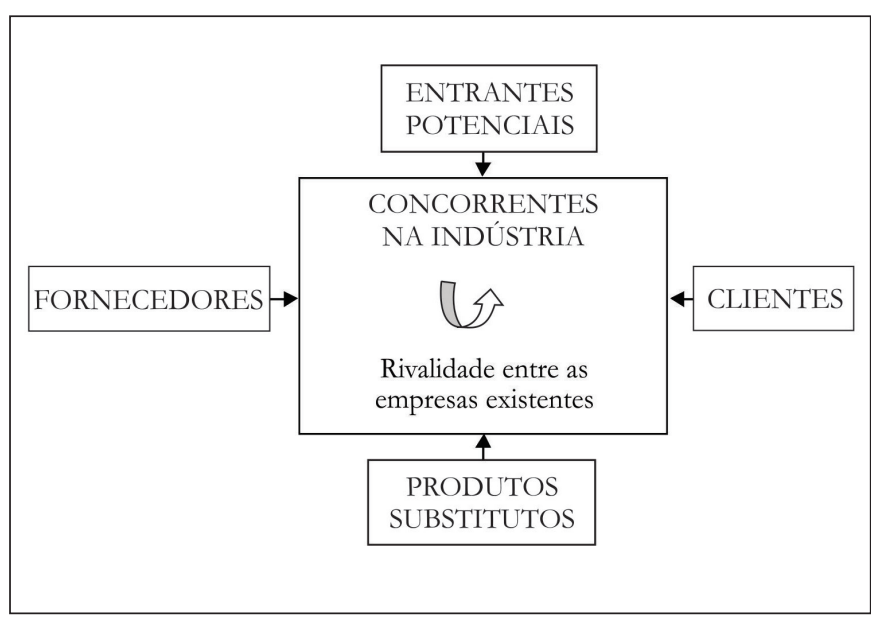

Figura 1 - Modelo das cinco forças que dirigem a concorrência na indústria

Fonte: PORTER, 1986.

A análise da estrutura industrial é a base fundamental do modelo proposto por Porter (1986), uma vez que essa estrutura tem uma forte influência na determinação das regras competitivas, que deverão ser observadas e compreendidas ao se analisar uma indústria, ou as empresas que a compõem. A análise da indústria deve apresentar as informações a respeito do tamanho, crescimento e estrutura do setor em que sua organização está inserida.

Um dos pressupostos básicos da proposta de Porter (1986) é que cada empresa que compete em uma indústria deve possuir uma estratégia competitiva. O fundamento da formulação de uma estratégia competitiva é entender como uma empresa interage com o seu ambiente de disputa empresarial.

A estratégia competitiva visa a estabelecer uma posição de lucratividade sustentável em uma determinada indústria, que vem a ser a arena competitiva onde forças distintas atuam. O modelo das cinco forças é inspirado na corrente da organização industrial, das ciências econômicas, e na premissa de que a estrutura da indústria define a conduta para 
otimizar a performance. Com isso, ele pretende explicitar as forças que atuam sobre as empresas.

Segundo Porter (1986), a intensidade da concorrência em uma indústria não é uma questão de coincidência; ao contrário, tem raízes em sua estrutura econômica básica e vai além do comportamento dos atuais concorrentes. As indústrias diferem em seu potencial de lucro final à medida que o conjunto das forças varia de intenso a relativamente moderado.

Carvalho e Laurindo (2006) consideram que as cinco forças propostas pelo modelo de Porter (1986) são fundamentais para a elaboração de estratégias competitivas, pois consideram a configuração da indústria na qual a empresa atua.

As forças competitivas são inversamente proporcionais à lucratividade da empresa - quanto mais intensas as forças em uma indústria, menor será sua lucratividade, assim como espera-se altos retornos nas indústrias nas quais as forças competitivas são moderadas. O objetivo da estratégia competitiva para uma empresa é encontrar uma posição dentro do setor em que ela possa melhor se defender contra essas forças competitivas ou influenciá-las em seu favor.

Quando estas forças são facilmente identificadas por todos os concorrentes é importante pesquisar em maior profundidade e analisar com mais afinco as fontes de cada força. Desta forma, pode-se destacar os pontos fortes e os pontos fracos apontando quais mudanças estratégicas podem resultar em melhores retornos, expondo quais as tendências e oportunidades são mais importantes para investimento de curto, médio elongo prazo a ser feito pela empresa para que esta mantenha seu grau de competitividade adequado dentro da indústria.

Todas as cinco forças competitivas determinam a intensidade da concorrência, como também a rentabilidade, sendo fundamental na formulação da estratégia atacar a força ou as forças que predominam.

\section{PROCEDIMENTOS METODOLÓGICOS}

\section{Escopo da pesquisa}

O presente trabalho analisou as cinco forças competitivas do setor de fertilizantes da região Nordeste por meio do modelo proposto por Porter (1986). Faz-se necessário ressaltar que foi considerada toda a estrutura operacional do setor para dar uma visão ampla e detalhada sobre os diversos elementos direcionadores (ou inibidores) da competitividade.

Para compor a estrutura da indústria de fertilizantes da região Nordeste do Brasil foram consideradas todas as empresas que possuem atuação regional e que são concorrentes diretas dentro deste setor. Foram excluídas empresas intermediárias e empresas parceiras, uma vez que os parâmetros adotados para analisar a competitividade se referem às empresas propriamente ditas.

\section{Variáveis}

Considerando o escopo a ser investigado, bem como o objetivo proposto para esta pesquisa, foram consideradas as seguintes variáveis:

- intensidade da concorrência atual: dinâmica concorrencial estabelecida entre as empresas pertencentes a uma determinada indústria;

- ameaça de novos entrantes: mecanismos presentes e atuantes em uma indústria e que são inibidores da entrada de novos concorrentes;

- ameaça de produtos substitutos: produtos disponíveis no mercado que possuem a capacidade de influenciar os níveis de preço praticados em uma indústria;

- poder de negociação dos clientes: dinâmica comportamental identificada entre as empresas pertencentes a uma determinada indústria e seus clientes;

- poder de negociação dos fornecedores: dinâmica comportamental identificada entre as empresas pertencentes a uma determinada indústria e seus fornecedores.

\section{Coleta e análise de dados}

Para determinar o método de coleta de dados foi considerado o caráter analítico e qualitativo da análise da competitividade, considerando as cinco forças do modelo de Porter (1986). Nesta pesquisa foi utilizada uma combinação dos métodos de análise documental e de entrevistas. Para Selltiz e Deuisch (1974), em alguns estudos é necessário comparar as 
descrições feitas sobre determinada atividade com o que realmente foi feito, dizendo que em tais casos é preciso empregar dois métodos de coleta de dados.

Em uma primeira fase, foram consideradas fontes secundárias para prover maior compreensão do setor de fertilizantes, bem como foram utilizados relatórios técnicos, websites especializados (CONAB, 2008; ANDA, 2008; IFA ENLARGED COUNCIL MEETING, 2008; IBGE, 2008) e análises setoriais para esclarecimentos adicionais necessários.

Andrade (1999) considera que uma pesquisa documentalestácentradanolevantamentodedocumentos (escritos ou não) para daro embasamento necessário à realização de uma pesquisa e que ela pode considerar documentos retrospectivos e contemporâneos.

Para Gil (1999), as vantagens inerentes à utilização de fontes documentais são as seguintes:

- possibilita o conhecimento do passado;

- possibilita a investigação de processos de mudança social e cultural;

- permite a obtenção de dados com menor custo;

- favorece a obtenção de dados sem o constrangimento dos sujeitos.

Na segunda etapa, foi realizado o desenvolvimento da pesquisa de campo propriamente dita, a partir da realização das entrevistas. Os dados foram coletados por meio de entrevistas pessoais, utilizando um roteiro semiestruturado, possibilitando a inclusão de tópicos adicionais.

Para Marconi e Lakatos (1996), uma entrevista é um procedimento utilizado no âmbito das Ciências Sociais para a coleta de dados, bem como para auxiliar a elaboração de diagnósticos.

Richardson (1989) considera que a utilização de entrevistas como técnica de coleta de dados possibilita um contato direto, no qual o pesquisador pode explicar e discutiros objetivos da pesquisa, além de responder dúvidas que os entrevistados tenham sobre certos aspectos questionados.

Merriam (1998), ao comentar os principais aspectos relacionados à utilização de entrevistas como técnica de coleta de dados, considera que, ao coletar dados por meio de entrevistas, há o envolvimento da determinação dos sujeitos a serem entrevistados. Desse modo, a escolha dos entrevistados depende do que o investigador deseja saber e sobre quais perspectivas a informação é almejada.
Foram realizadas entrevistas para a coleta das informações necessárias para a elaboração deste trabalho. Foram entrevistados dois executivos que atuam no setor de fertilizantes. Os critérios para a definição dos entrevistados foram os seguintes:

- experiência profissional consolidada no setor;

- posição hierárquica superior, capaz de dar acesso às principais informações estratégicas das empresas nas quais eles atuam.

A análise dos dados foi realizada por meio do confronto entre as respostas obtidas nas entrevistas executadas e os aspectos conceituais inerentes às cinco forças do modelo de análise da indústria proposto por Porter (1986).

\section{APRESENTAÇÃO E DISCUSSÃO DOS RESULTADOS}

Considerando o objetivo proposto, foi analisado o setor de fertilizantes no Nordeste. Podemos destacar as principais forças competitivas e descrevê-las de acordo com o modelo das cinco forças considerado.

\section{Intensidade da concorrência}

Sobre a intensidade da concorrência, foi observado no setor grande número de empresas que estão localizadas em diversos Estados do Nordeste do Brasil (Bahia, Pernambuco, Maranhão, Alagoas e Sergipe). Essas empresas estão instaladas principalmente em regiões próximas a regiões litorâneas, graças à recepção de insumos importados. Também existem algumas empresas que estão localizadas em regiões mais próximas dos mercados consumidores, a exemplo do oeste baiano e sul do Maranhão. Estão instaladas oito empresas na Bahia, duas em Pernambuco, duas no Maranhão, cinco em Alagoas e duas em Sergipe. Todas elas participam ativamente do mercado e importam insumos do mercado externo.

Estas empresas se caracterizam por serem predominantemente compostas por capitais estrangeiros, restando poucas pertencentes a grupos nacionais. Algumas das unidades de mistura pertencem 
a um mesmo grupo e estão instaladas em Estados diferentes. Podem ser destacadas apenas oito principais grupos que atuam neste mercado: Fertipar, Yara, Bunge, Heringer, Mosaic, Roullier, Galvani e JL.

A intensidade da concorrência é caracterizada como muito elevada, graças ao tipo de produto ser de qualidade similar, tendo suas garantias estabelecidas e controladas pelo governo federal, pelo Ministério da Agricultura.

A indústria de fertilizantes é dependente de escala de produção. Deve-se produzir baseado em custos cada vez mais baixos, o que faz com que a concorrência seja muito acirrada e os grandes grupos estejam disputando firmemente por posições no mercado a partir da venda de volumes maiores, normalmente com margens menores. Estas posições foram sendo galgadas historicamente por compras das empresas menores por grandes grupos nacionais e multinacionais, aumentando cada vez mais a disputa pelo mercado.

Por ser insumo básico para produção agropecuária, o crescimento do setor tem interdependência com os resultados obtidos nas principais culturas agrícolas, destacando-se soja, milho e canade-açúcar, que são os maiores consumidores de fertilizantes. Essa interdependência está relacionada principalmente a três fatores distintos:

a) a expansão da área plantada;

b) o aumento da produtividade agrícola;

c) os preços no mercado.

A expansão da área faz com que ocorra aumento no consumo de fertilizantes proporcional ao aumento da área plantada de acordo com o consumo médio de cada cultura. Todas as formas de aumento da produtividade agrícola estão relacionadas direta ou indiretamente com o aumento no consumo de fertilizantes. O fator preço das culturas agrícolas responde indiretamente na indústria de fertilizantes, da seguinte forma: quando o preço proporciona uma rentabilidade considerável para o produtor, bem como para a cadeia produtiva, há estímulo para a expansão da área plantada e uso de tecnologia para o crescimento vertical da produção. Quando o preço não está favorável, os produtores reduzem a capacidade financeira para honrar seus compromissos, enfrentam restrições de crédito e diminuem a área da lavoura.
Portanto, quando o crescimento da indústria é lento, isto é refletido no setor, aumentando a disputa pelas empresas para manter o volume de produção sem que haja aumento de risco de crédito e inadimplência.

Os movimentos competitivos das empresas são facilmente observados pelos concorrentes. Esses movimentos fazem com que as empresas que têm metas mais agressivas promovam retaliações vigorosas às empresas que estão disputando por maior espaço no mercado. As reações atingem todas as outras empresas do setor, forçando a diminuição das margens, pois os custos de armazenamento se elevam e o giro dos estoques assume maior importância relativa. Deste modo, os preços podem atingir valores inferiores aos limites capazes de assegurar a rentabilidade desejável.

\section{Ameaça de novos entrantes}

Com relação à ameaça de novos entrantes, esta é entendida como sendo a possibilidade de novas empresas na indústria. As barreiras de entrada são os elementos que dificultam o ingresso de um novo participante; associadas às possíveis retaliações, elas inibem a entrada de novos participantes.

A ameaça de novos entrantes dentro do mercado de fertilizantes do Nordeste pode ser considerada pequena, pois, com exceção da Bahia (que responde por mais de $50 \%$ de todo o consumo de fertilizantes da região), o mercado é relativamente pequeno na maioria dos Estados, quando comparado com outros mercados.

Pode ser observada a existência de um movimento de concentração no mercado e a busca de maiores parcelas de participação por grupos cada vez maiores, comportando-se com movimentos similares aos das empresas que iniciam no mercado, tentando ganhar a todo custo parcela de mercado e firmar uma posição.

A economia de escala é a principal barreira de entrada no setor de fertilizantes, pois as empresas precisam ter custos cada vez menores para concorrer no mercado, e isto é conseguido significativamente com um maior volume de compras, produção e vendas. Os custos administrativos e de produção (custos fixos) são altos para quem tem um pequeno volume, porque a margem agregada por unidade do produto é pequena. O compartilhamento de custos 
é uma opção para fábricas de pequeno volume, mas que fazem parte de um grupo maior em âmbito nacional, o que permite fazer importações e compras em conjunto com outras empresas.

Outra importante barreira de entrada é a necessidade de capital. A empresa para entrar neste setor precisa ter um aporte financeiro muito bom, pois os volumes financeiros empregados são altos.

$\mathrm{O}$ acesso às matérias primas é outro fator que dificulta a entrada para uma nova empresa, pois tanto a importação quanto a compra no mercado nacional destes produtos não são processos simples e facilmente acessíveis. Os arranjos de fornecimento dependem de contratos anuais de fornecimento, o que desfavorece o iniciante. Os preços ofertados também nem sempre são atrativos para empresas iniciantes ou de menor porte.

A localização é um ponto essencial para a boa competitividade de uma empresa no setor de fertilizantes. Esse fator está principalmente ligado à logística do setor. É o ponto de partida para uma boa capacidade de disputar no mercado com custos reduzidos compatíveis com outras concorrentes. A localização, a necessidade de capital e a escala são os fatores preponderantes como barreiras à entrada de novos competidores.

Nos principais mercados consumidores de fertilizantes é difícil conseguir áreas atraentes disponíveis. As principais áreas de interesse para as empresas se instalarem são as que estão o mais próximo possível dos portos receptores das matérias-primas (graneleiros sólidos), e existem muitas restrições para se conseguir áreas nestas localidades. Os portos do Recife, PE, Maceió, AL, Candeias, BA, e São Luiz, MA, são os principais em recebimento de matériaprima; hoje não se tem áreas disponíveis dentro destes portos para instalação de indústrias, o que já significa uma barreira de entrada nestes mercados.

Praticamente não existem barreiras de saída do negócio, ou estas são baixas. Fazendo a análise da relação das barreiras de entrada e saída com a rentabilidade e riscos do negócio, pelo quadro de barreira e rentabilidade proposto pelo modelo, verifica-se que as barreiras de entrada são consideradas como medianas e as de saída, baixas. Portanto, existe a tendência de se ter retornos estáveis e medianos dentro do setor.

\section{Ameaça de produtos substitutos}

De uma maneira geral, as empresas estão competindo com produtos substitutos que impõem um teto na maximização dos lucros em uma determinada indústria. Pode-se dizer que todas as indústrias competem em termos amplos, com produtos substitutos de outras indústrias, que freiam os preços dos produtos ofertados ao mercado.

Os fertilizantes aparentemente não possuem produtos substitutos, porém, isso não é verdade. Apenas são difíceis de ser percebidos como tais.

O mais fácil a ser visto como substituto dos fertilizantes é o adubo orgânico, pois este pode reduzir parcialmente as quantidades de fertilizantes utilizadas em uma dada condição de solo, água e planta. O adubo orgânico é colocado parcialmente, pois, dadas as características dos solos da região (de forma geral muito pobre), sempre são requeridos alguns nutrientes em maior quantidade para atender à demanda de nutrientes exigida por uma dada cultura ou mesmo variedade. Estes nutrientes dificilmente serão supridos apenas com a adubação orgânica, pois, por serem muito menos concentrados em nutrientes que os fertilizantes químicos, teriam que ser colocadas grandes quantidades para suprir as necessidades, e assim obter a produção adequada, o que inviabilizaria seu uso por motivos primeiramente econômicos, mas também por capacidade de suprimento da quantidade de adubo orgânico exigida.

De toda forma, a agricultura orgânica se vale de um diferencial de preço para compensar a baixa eficiência produtiva por falta de nutrientes para a cultura, sendo um produto tido como diferenciado e sendo um competidor com o consumo de fertilizantes.

Além disso, na medida em que os mesmos movimentos ecológicos que apoiam o consumo de produtos orgânicos trabalham para a proteção de nossas matas, eles defendem a redução da abertura de novas áreas de plantio por meio da derrubada destas.

Com o crescimento da população, bem como da demanda por alimentos, não existe outra maneira de se diminuir a abertura de novas áreas sem que haja o incremento vertical da produção, ou seja, o aumento da produtividade. Portanto, esses grupos acabam por fazer um papel ora de defensores do uso de fertilizantes, ora contrários ao seu uso. 


\section{Poder de negociação dos fornecedores}

Os fornecedores de uma indústria podem exercer papel decisivo sobre seu contexto competitivo na medida em que eles podem ameaçar ou impor aumentos de preços e a indústria não tem possibilidade de repassá-los para seus clientes. Essas perspectivas podem sinalizar ameaças sobre as margens de lucro praticadas. Os fornecedores possuem poder de barganha com seus clientes. Quanto maior este poder de barganha, mais a indústria em questão terá vulnerabilidade no seu negócio e limitação de crescimento.

$\mathrm{Na}$ indústria de fertilizantes, o poder de negociação dos fornecedores é muito intenso e está bem definido de acordo com a lei básica da economia da oferta e procura. Por se tratar de commodities, os preços das matérias-primas são claramente definidos pelo mercado.

Este poder de negociação dos fornecedores está presente no setor de fertilizantes, porque a produção é muito concentrada, em âmbito mundial, por poucas empresas, sendo dominado por estas companhias que formam grandes oligopólios internacionais. Dentre os principais nutrientes produzidos, o nitrogênio, o fósforo e o potássio são os que exercem maiores influências de preços, graças aos altos volumes consumidos pelas lavouras e, consequentemente, por serem os de maiores produção.

A indústria de produção de potássio é a mais concentrada, sendo dominada por cerca de cinco empresas no mundo. Este nutriente é o mais consumido no Brasil, e este consumo também tem reflexos na região Nordeste. O Brasil tem uma produção muito pequena desse nutriente, chegando a importar quase $90 \%$ do que é consumido. Essa produção é feita por uma única empresa, a Companhia Vale do Rio Doce. Este cenário faz com que a indústria de fertilizantes seja dependente dos preços impostos pelos fornecedores deste nutriente, tentando repassar aos produtores os constantes reajustes sofridos.

O fósforo é encontrado na natureza como fosfatos de rocha nas jazidas que ocorrem por todo o mundo. A produção de fosfatados em âmbito mundial está concentrada principalmente no norte da África, estando as maiores reservas em países como Marrocos (60\%), China (15\%), Estados Unidos (4\%), África do Sul (4\%) e Jordânia (2\%), que detêm 85\% das 56 milhões de toneladas das reservas da rocha. Também é uma indústria bastante concentrada, mas um pouco menos que a do potássio, pois o Brasil produz cerca de $60 \%$ da necessidade deste nutriente. Entretanto, no Nordeste brasileiro, a logística de transporte por rodovias inviabiliza a competitividade desse nutriente, sendo o importado mais vantajoso economicamente para maior parte do consumo do Nordeste. De toda forma, os fornecedores também detêm forte poder de negociação.

A indústria fornecedora de nitrogênio é a menos concentrada internacionalmente, mas também é considerada concentrada em termos de poder de barganha, embora um pouco menos que a dos outros nutrientes. Esta indústria está ligada à cadeia de produção de petróleo, em que a principal matériaprima para a produção dos produtos nitrogenados é o gás natural. Os países produtores de gás natural com custos baixos possuem grandes perspectivas de crescimento na produção de fertilizantes nitrogenados, como também possuem grande poder de negociação do produto.

As ações dos fornecedores de nitrogenados estão principalmente relacionadas às flutuações dos preços do barril de petróleo, sendo estas, ao lado das flutuações da taxa de câmbio, os principais fatores influenciadores dos preços.

Pode-se afirmar que na indústria de misturas de fertilizantes, o poder de barganha dos fornecedores é intenso, pois a produção de matérias-primas é dominada por grandes oligopólios que regulam a oferta de produtos no mundo. Os fornecedores não possuem produtos substitutos para regulação dos preços. Para a indústria de misturas, o insumo é o próprio produto que será entregue na ponta, com industrialização simples de mistura e ensaque; esta é totalmente dependente dos fornecedores.

\section{O poder de barganha dos compradores}

Há uma similaridade com o poder de barganha dos fornecedores. O volume anual comprado e o perfil de pagamento são os fatores que regem este poder. Quanto maior o volume de um cliente equanto mais segurança a empresa tem no recebimento, mais a disputa sobre a determinação dos preços a serem praticados é acirrada.

Os compradores têm facilidades para substituir marcas porque os produtos são padronizados. Portanto, a indústria não oferece nenhum custo de mudança para os compradores, fazendo com que 
a qualquer momento o comprador possa comprar de todas as empresas que possa atender, sendo os pontos mais importantes para a escolha o preço, a disponibilidade para a entrega e o grau de relacionamento com as pessoas da empresa.

Os fertilizantes representam uma fração significativa dos custos de produção agrícola, fazendo com que os produtores busquem reduzir ao máximo os gastos com este insumo. Muitas vezes, com a intenção de reduzir custos, os compradores chegam até a colocar a parte técnica em segundo plano, ou seja, mudam as formulações ou as quantidades indicadas como a que traria o melhor resultado para lavoura. Esta prática é principalmente vista quando os preços dos produtos da lavoura em questão estão baixos, pois os custos dos fertilizantes passam a ser tão importantes, que muitos acham que nesta redução pode-se ter alguma lucratividade.

Na região Nordeste, os compradores podem ser distinguidos em grandes produtores, revendedores, cooperativas, pequenos e médios produtores, mas esta classificação assume aspectos relativos dentro da região. Por exemplo, em certa parte do Nordeste, um cliente que compra 100, 200 ou 300 toneladas de fertilizantes pode ser considerado grande, enquanto que em outra parte, um produtor que compra esta mesma quantidade poderá ser considerado médio ou até mesmo pequeno. Isso é importante para que se tenha o entendimento de que o porte do cliente depende da localização na qual ele está inserido e não apenas do volume em si que ele compra.

Os grandes clientes são assim classificados de acordo com o volume proporcional de suas compras em um determinado mercado. Eles são representados principalmente pelos produtores de grãos da região oeste da Bahia e do sul dos Estados do Maranhão e Piauí. Também são consideradas grandes as usinas e destilarias de cana-de-açúcar, concentradas na região do litoral que vai de Alagoas ao Rio Grande do Norte, bem como pelas grandes fazendas produtoras e exportadoras de frutas no Vale do São Francisco e região de Mossoró.

Por fim, os compradores também têm um poder de barganha expressivo e importante para manter o equilíbrio dos preços desta commodity, sendo eles atendidos diretamente pela indústria ou pelos revendedores e cooperativas regionais, que forçam os preços para baixo buscando uma eficiência na produção agrícola, como também a melhoria contínua das indústrias de misturas.

\section{CONSIDERAÇÕES FINAIS}

O objetivo deste trabalho foi identificar e analisar as forças que regem a competitividade na indústria de fertilizantes no Nordeste pelo método das cinco forças de Porter.

Verificou-se que, com exceção dos produtos substitutos, todas as forças afetam a concorrência nesta indústria, influenciando na capacidade daindústria de se manter mais ou menos competitiva ao longo do tempo, levando-se em consideração que estas mesmas forças continuem regendo a competitividade nesta indústria.

A intensidade da concorrência é alta, mas as principais barreiras de entrada estão relacionadas ao volume e à capitalização da empresa. É um mercado bastante aberto, em que a estratégia de custos éprioritária. Algumas empresas tentam se diferenciar no mercado, entretanto o investimento em marketing é muito tímido e as empresas investem no trabalho personalizado e de relacionamento dos seus agentes com os clientes.

A ameaça de produtos substitutos é muito pequena, pois o único produto para concorrer, fertilizante orgânico, não possui escala e possivelmente apresente custos bem mais altos para o produtor, não sendo identificado como uma força competitiva relevante.

O poder de barganha dos fornecedores é uma força muito importante, mas está relacionada à economia de escala da empresa - portanto, a empresa precisa participar com um volume adequado, ou individualmente ou considerando o grupo de empresas da qual faz parte. Empresas de pequeno porte têm poucas chances de teruma boanegociação com os fornecedores.

O poder de barganha dos compradores possui muitas similaridades com o poder dos fornecedores e está principalmente ligado ao volume consumido, bem como ao perfil e capacidade de pagamento. Normalmente, estes compradores não possuem problemas para mudar a escolha de uma empresa, pois não acarretará nenhum custo de mudança. O relacionamento interpessoal entre vendedor e comprador ainda é o ponto mais importante na diferenciação da indústria com os clientes.

Pode-se dizer que há economias de escala quando os custos médios de produção decrescem com o aumento do tamanho da planta industrial. A escala de produção favorece a captação a juros mais baixos, maior flexibilidade para o fornecimento de crédito, vantagem logística e financeira na aquisição de matéria-prima importada e maior poder no jogo competitivo na indústria. 
Com a redução da capacidade ociosa, os custos médios decrescem, pois é menor o peso relativo dos custos fixos de produção. No entanto, é importante mencionar que a sazonalidade do consumo de fertilizantes leva à existência de capacidade ociosa durante parte do ano, o que aumenta os custos de estoques e matérias-primas. As empresas do setor têm adotado estratégias de comercialização para estimular as retiradas antecipadas nos meses de entressafra.

A logística assume papel decisivo na eficiência do processo de aquisição de matérias-primas e também no processo de escoamento de produtos. A logística eficiente pode estar relacionada com a maior coordenação do suprimento de insumos e também com a formatação de parcerias.

Embora a liderança em custos seja condição primordial para a competitividade em commodities, mudanças no ambiente competitivo e institucional, com discussões relacionadas a padrões de qualidade, segurança alimentar e proteção ambiental, estão ganhando importância e têm determinado a adoção de estratégias diferenciadas por parte de algumas empresas.

Pode-se concluirque as empresas produtoras de misturas fertilizantes adotam estratégias baseadas na liderança em custos, em que a busca de economias de escala, a baixa capacidade ociosa e a logística eficiente são fatores determinantes do desempenho.

\section{REFERÊNCIAS}

AAKER, D. A. Administração estratégica de mercado. 5. ed. Porto Alegre: Bookman, 2001.

ASSOCIAÇÃO NACIONAL PARA A DIFUSÃO DE ADUBOS - ANDA. Produto e mercado de fertilizantes. In: ENCONTRO NACIONAL DE PRODUÇÃO E ABASTECIMENTO DE BATATA - ABBA, 13., 2007, Holambra. Anais... Holambra: ANDA, 2007.

ASSOCIAÇÃO NACIONAL PARA A DIFUSÃO DE ADUBOS - ANDA. 2006. Disponível em: <www.anda. org.br>. Acesso em: 3 jan. 2008.

ANDRADE, M. M. de. Como preparar trabalhos para cursos de pós-graduação. 3. ed. São Paulo: Atlas, 1999.

CARVALHO, M. M. de; LAURINDO, F. J. B. Estratégia competitiva: dos conceitos à implementação. 2. ed. São Paulo: Atlas, 2006.
COMPANHIANACIONALDEABASTECIMENTOCONAB. Safras 1990 a 2004: séries históricas. Disponível em: <www.conab.gov.br>. Acesso em: 9 jan. 2008.

DIAS, V. P.; FERNANDES, E. Fertilizantes: uma visão global sintética. BNDES Setorial, Rio de Janeiro, n. 24. p. 97-138, 2006.

GIL, A. C. Pesquisa social. 5. ed. São Paulo: Atlas, 1999.

IFA ENLARGED COUNCIL MEETING, 33., Doha. Proceedings electronics... Doha: IFA, 27-29 Nov. 2007. Disponível em: <http://www.fertilizer.org/ifa/ Home-Page/LIBRARY/Conference-papers/EnlargedCouncil-Meetings/2007-IFA-Council>. Acesso em: 29 dez. 2007.

INTERNATIONAL FERTILIZER INDUSTRY ASSOCIATION - IFA. Fertilizer indicators. 2nd ed. Paris: IFA, 2002.

INSTITUTOBRASILEIRODEGEOGRAFIA-IBGE. Censo agropecuário. Disponível em: <www.ibge.gov. br>. Acesso em: 10 jan. 2008.

MARCONI, M. de A.; LAKATOS, E. M. Técnicas de pesquisa. 3. ed. São Paulo: Atlas, 1996.

MERRIAM, S. Qualitative research and case study applications in education. 3rd. ed. San Francisco: JosseyBass, 1998.

OLIVEIRA, D. de P. R. de. Estratégia empresarial e vantagem competitiva: como estabelecer, avaliar e implementar. 3. ed. São Paulo: Atlas, 2001.

PORTER, M. E. Estratégia competitiva: técnicas para análise de indústrias e da concorrência. 7. ed. Rio de Janeiro: Campus, 1986.

RICHARDSON, R. J. Pesquisa social. 3. ed. São Paulo: Atlas, 1989.

SELLTIZ, J.; DEUISCH, C. Métodos de pesquisa nas relações sociais. São Paulo: EPU, 1974.

VASCONCELOS, F. C. de; CYRILO, Á. B. Vantagem competitiva: os modelos teóricos atuais e a convergência entre estratégia e teoria organizacional. In:BERTERO, C. O. (Org.). Gestão empresarial. São Paulo: Atlas, 2006. p. 63-81.

Recebido: 22/06/2008 Received: 06/22/2008

Aprovado: 10/07/2008

Approved: 07/10/2008 